\title{
IMPACT OF AVIATION FUEL ON DURABILITY OF DIESEL COMMON RAIL INJECTION SYSTEM
}

\author{
Tomas Mickevicius, Stasys Slavinskas, Gvidonas Labeckas \\ Vytautas Magnus University, Lithuania \\ tomas.mickevicius1@vdu.lt, stasys.slavinskas@vdu.lt, gvidonas.labeckas@vdu.lt
}

\begin{abstract}
The article presents the experimental test results reflecting the impact of aviation fuel on durability of the main components of the Common Rail Direct Injection (CRDI) system used in light-duty diesel vehicles. The two identical fuel injection systems operating with turbine type Jet-A1 fuel and normal diesel fuel were prepared for the durability tests. The high-pressure fuel supply pump is one of the most overloaded components in the fuel injection system. Durability of the injection system largely depends on the lubricating properties of diesel fuel. The reduced durability of the fuel injection system's components, such as fuel supply pump and injectors, sometimes can be ascribed to a lack of the lubricating quality of diesel fuel. Considering the relatively poor lubricating properties of the Jet-A1 fuel one should remember that the main moving parts of the fuel system are affected by friction while working under the most difficult conditions in the diesel engine. Overall performance of the fuel delivery system and the surface roughness of the moving parts of the pump were evaluated and measured before and after the laboratory tests to determine the Jet-A1 fuel-made effects on durability of the high pressure fuel pump. The tests were carried out at the high injection pressure variable from $10 \mathrm{MPa}$ till $110 \mathrm{MPa}$ (load) during 300 hour durability tests. An optical microscope was used to measure the wear off surfaces and analyse the effect of the aviation fuel on the surface micro structure of the studied parts. The High-Frequency Reciprocating Rig (HFRR) method was used to measure the resulting wear on the ball to evaluate the lubricity properties of Jet-A1 fuel. The values of the wear scar diameter (WSD) obtained with Jet-A1 fuel were compared to the respective values measured with the reference diesel fuel. The microscopic photographs of the wear scar diameters obtained on the test balls for the above mentioned fuels are presented in the paper.
\end{abstract}

Keywords: diesel fuel, aviation Jet-A1 fuel, lubricity, high-frequency reciprocating rig, wear scar.

\section{Introduction}

More efficient using of fossil (mineral) fuels and the increased interest in application of alternative and renewable fuels for diesel engine powering are currently of particular importance in relation with the depletion of the world's mineral fuel resources. The transport sector is one of the key aspects in the economic development of the local regions and is directly dependent on the crude import and export processes. The pollutant emissions generated by the transport sector have a major impact on the air quality and human health. The permanently growing demand for the transportation machines and the quantity of goods to be transported increases the volumes of combustion products emitted from internal combustion engines that pollute the environment and promote the greenhouse effect. The agriculture and transport sectors can be regarded as the largest fossil fuel consumers and therefore are the main contributors to the environmental pollution.

Diesel fuel is currently the most popular type among other motor fuels. Consumption of diesel fuel has been growing steadily over the last two decades. Jet fuel is a special-purpose blended fuel extracted during distillation of crude oil. Kerosene distilled from mineral oil or shale oil is the main component in many Jet fuels. The fuel Jet-A1 is actually a kerosene type turbine aviation fuel used for powering of turbine engines in ground-aerial machines [1].

Specific properties of fuel, such as density, viscosity, calorific value, cetane number, freezing point, etc. change when using renewable or alternative fuels. The physical properties related features affect the fuel delivery and injection characteristics and thus the quality of the combustible mixture, which in turn affects the performance and the ecological parameters of the diesel engine.

The experimental test results have demonstrated the potential operation of the diesel engine with aviation turbine-type Jet A-1 fuel without significant changes in the engine performance and efficiency [2;3]. However, the long-term impact on the fuel injection system components of Jet A-1 fuel having lower density, viscosity and poorer lubricity properties compared to conventional diesel fuel still remains unexplored to a greater extent and thus requires specific experimental tests. 


\section{Materials and methods}

The experimental research was carried out in the fuel equipment testing laboratory of the Power and Transport Machinery Engineering Institute at the Faculty of Agricultural Engineering of the Vytautas Magnus University - Agricultural Academy.

The Common Rail injection system has been used for the experimental tests. The principal diagram of the test bench is shown in Fig. 1. The electric delivery pump (2) mounted in the fuel tank (1) supplied the fuel through the fine-porous fuel filter (3) to the high pressure pump (4).

The two Bosch-type CR/CP1S3/R65/10 high-pressure fuel pumps were connected by the same belt driven in the same mode. Moreover, both fuel pumps maintained the changeable pre-set pressure values of 20,40,60,80,100, and $110 \mathrm{MPa}$ depending on the on-going time of every 30 minutes. Powered by an electric motor, the high-pressure pumps operated continuously to build up the needed injection pressure, which was retained in the volume of the fuel accumulator (7). The pressure was adjusted via a pressure regulator (5) connected to the control unit (8). The sensor installed in the pressure accumulator transferred a signal to the control unit to evaluate the present fuel pressure.

Diesel fuel (DD) and aviation fuel (JET A1) have been used for the experimental research. During the reliability tests of the fuel pumps the fuel-flow was cooled, so that its temperature does not exceed $35^{\circ} \mathrm{C}$.

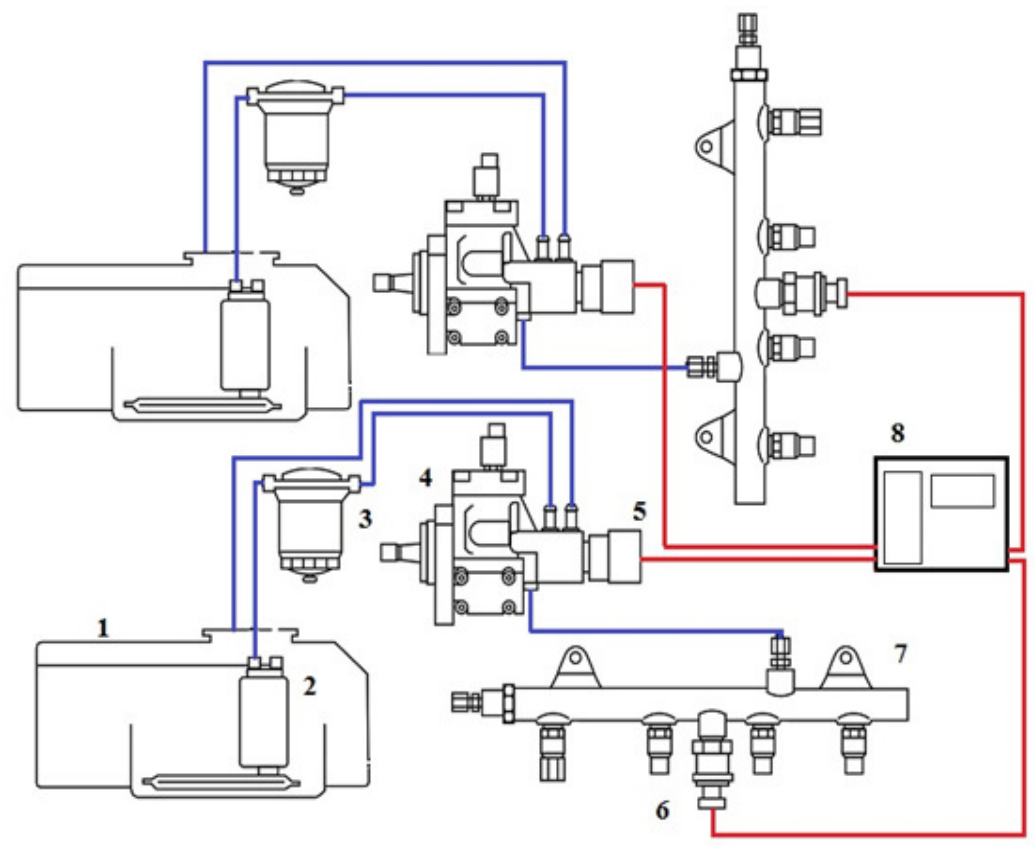

Fig. 1. Scheme of testing stand: 1 - fuel tank; 2 - fuel supply pump; 3 - fuel filter; 4 - high-pressure pump; 5 - pressure control valve; 6 - rail-pressure sensor; 7 - fuel rail; 8 - fuel pressure control unit

Analysis of the lubricating properties of the fuel was performed on the basis of the wear data obtained by using the High Frequency Reciprocating Rig (HFFR) apparatus. Lubricity of the fuel was determined on the basis of the wear traces formed on the swinging ball due to the contact with the stationary plate immersed into the tested fuel. The testing procedures were performed according to the international standard ISO 12156 requirements [5;6]. During the lubricity tests the fuel temperature was maintained to be of a constant value of about $30^{\circ} \mathrm{C}$. The intensity of the balls' surface wear images was evaluated by using the Nikon Elipse MA100 optical microscope.

\section{Results and discussion}

The primary purpose of the fuel-injection system is to supply fuel to the cylinder of a diesel engine. The fuel-injection pump builds up the fuel pressure needed for injection and then at the required rate delivers the fuel to the engine [4]. The fuel delivery rates determined for the various pressure values built up by both fuel pumps at the very beginning $(0 \mathrm{~h})$ of the experiments are illustrated by the columns in Fig. 2. As it can be seen, the fuel delivery rate did not change greatly and 
sustained at the constant level of about $11 \mathrm{~mm}^{3} \cdot \mathrm{s}^{-1}$ until the injection pressure reached the $60 \mathrm{MPa}$. After then, the fuel delivery rate started to decrease gradually with every next increase in the fuel injection pressure due to insufficient power of the electrical motor.

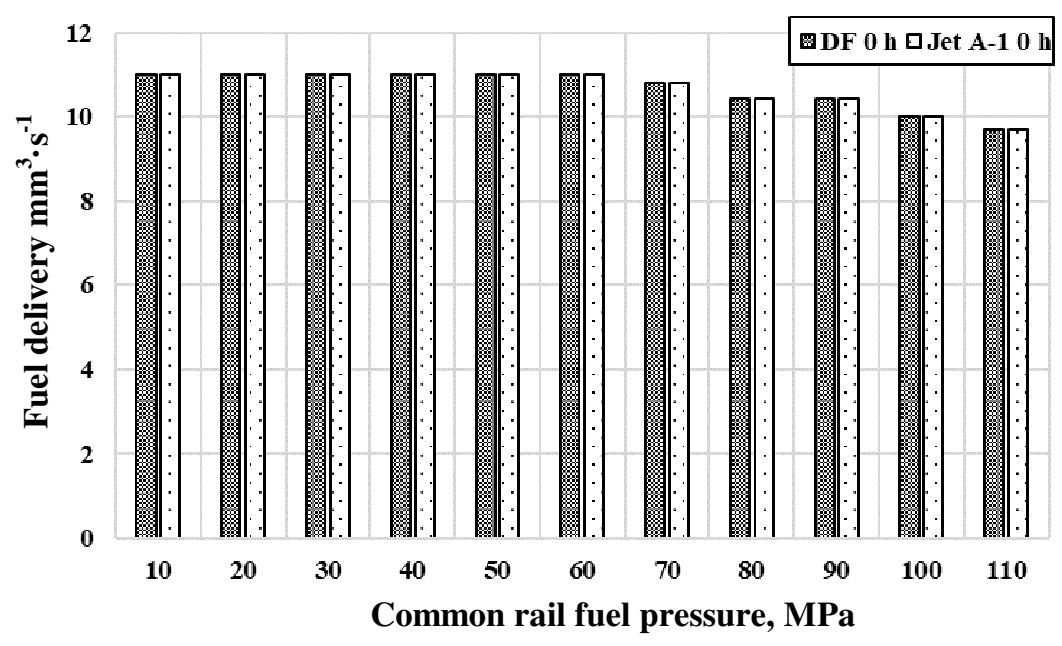

Fig. 2. Dependency of fuel delivery rate on fuel injection pressure built up by fuel pump at the beginning $(0 \mathrm{~h})$ of reliability tests

Analysis of the obtained results shows (Fig. 3) that after the 300 hours of operation the fuel delivery rate decreased by about $0.5-1.0 \mathrm{~mm}^{3} \cdot \mathrm{s}^{-1}$ in both fuel pumps tested. Nevertheless, the wear of the plunger-barrel units seems as being more intensive in case of using a lighter aviation turbine Jet A1 fuel rather than normal diesel fuel. The relative decrease in the fuel delivery rate was about $1 \%$ greater with aviation Jet A-1 fuel at the injection pressure of $50 \mathrm{MPa}$ and, unfortunately, the resulting decrease in the fuel delivery rate reached the $6.5 \%$ after the injection pressure was increased up to 110 $\mathrm{MPa}$. It can be assumed from observation of the test results that the wear intensity of the plungerbarrel unit was somewhat greater in case of using Jet A-1 fuel and, for this reason, the delivery rate of Jet A-1 fuel was reasonably lower due the resulting leakage of the fuel. Nevertheless, the fuel delivery rates were at the acceptable level for both fuel injection pumps.

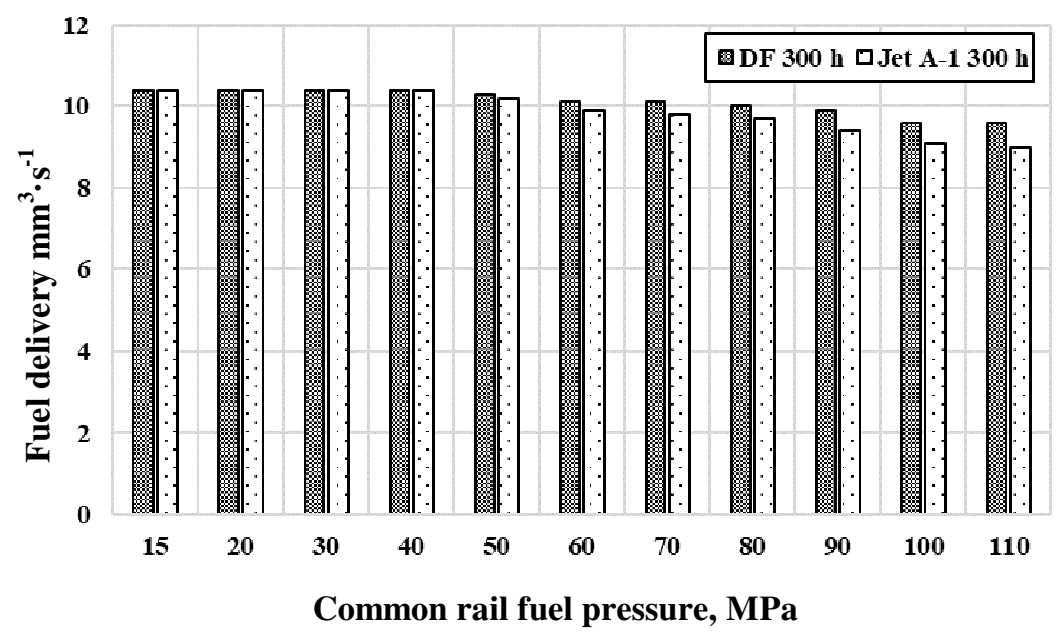

Fig. 3. Dependency of fuel delivery rate on fuel injection pressure built up by fuel pump at the end $(300 \mathrm{~h})$ of reliability tests

The plunger-barrel unit is one of the most overloaded components of the fuel system [6]. It can be assumed that this element is one of the most friction-sensitive units operating in the heaviest friction conditions in the diesel engine and therefore it can be chosen to evaluate the effects done by the relatively worse lubricating properties of Jet A-1 fuel. The columns in Fig. 4 show how the average wear scar diameter (WSD) of the test ball changed, when using normal diesel fuel, aviation Jet A-1 fuel and their respective blends. The test results demonstrate that according to maximum decrease in 
the diameter of $0.6 \mathrm{~mm}$ the biggest scar wear was obtained, when using neat (100\%) aviation Jet A-1 fuel (Fig. 4). The minimum wear scar diameter of $0.28 \mathrm{~mm}$ was recorded with normal diesel fuel. At the same time, the wear scar diameter was equal to $0.58 \mathrm{~mm}$, when running with diesel and Jet A-1 fuel blend JET 50 prepared in 50:50 proportions.

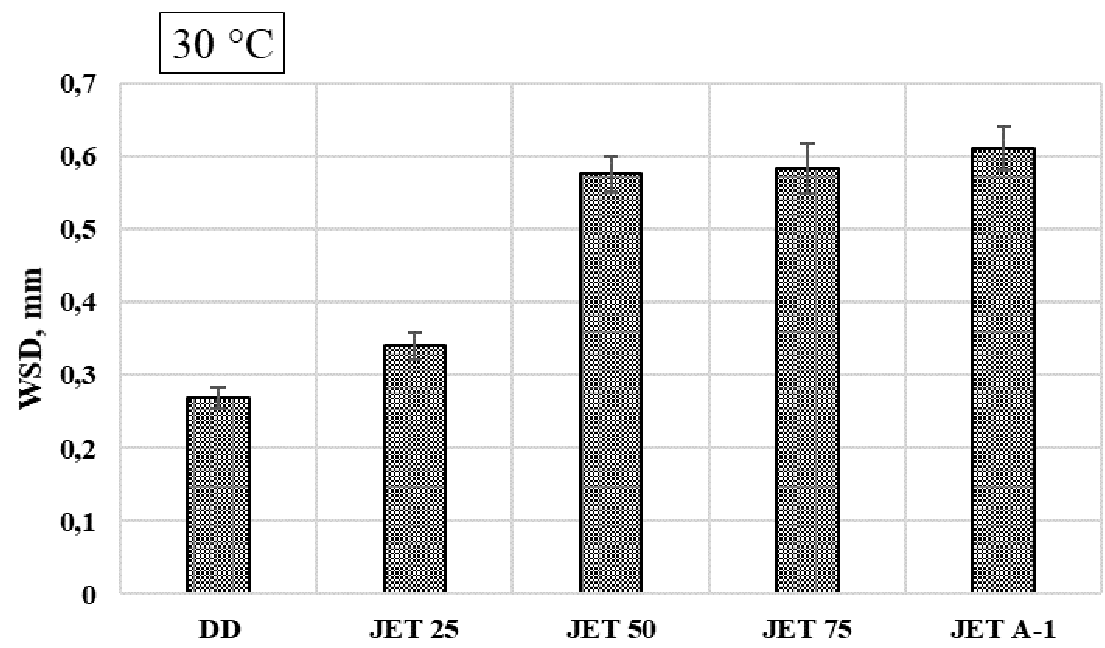

Fig. 4. Dependency of average wear scar caused by diesel fuel, neat $(100 \%$ ) aviation Jet A-1 fuel and their respective 25, 50, 75 (by volume) blends

The changing trends in the friction moment variation coefficients determined by the HFRR apparatus are illustrated by the diagrams presented in (Fig. 5). As it can be seen in the diagrams, the friction moment was relatively lower and its variation coefficient was more stable, when using normal diesel fuel. The friction coefficient of 0.1 was obtained at the 8-9 minute after start of investigation of neat aviation fuel. After that the friction coefficient decreased to 0.08-0.09 and sustained at about the same level during the remaining time of the test. The lowest friction coefficient of about 0.055 was recorded after 30 minutes run (test) with diesel fuel (Fig. 5).

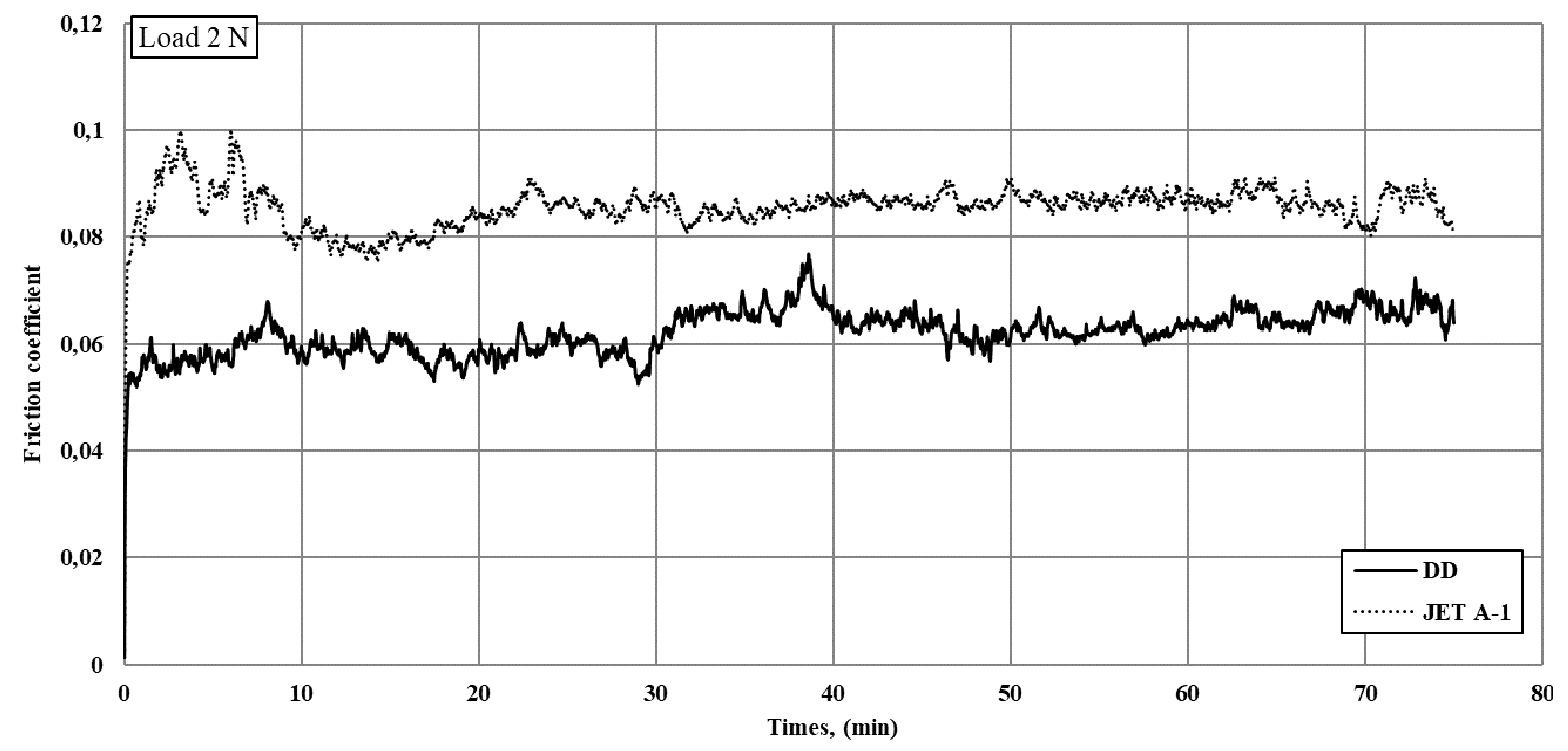

Fig. 5. Variation of friction coefficient for aviation fuel Jet A-1 and diesel fuel as function of time

Fig. 6 shows the images of the worn steel ball surface.

The obvious difference in the worn surface area can be seen by comparing the friction pairs lubricated with different fuels. The images show that using diesel fuel resulted in a relatively lower worn surface area compared to that are caused by aviation Jet A-1 fuel. 


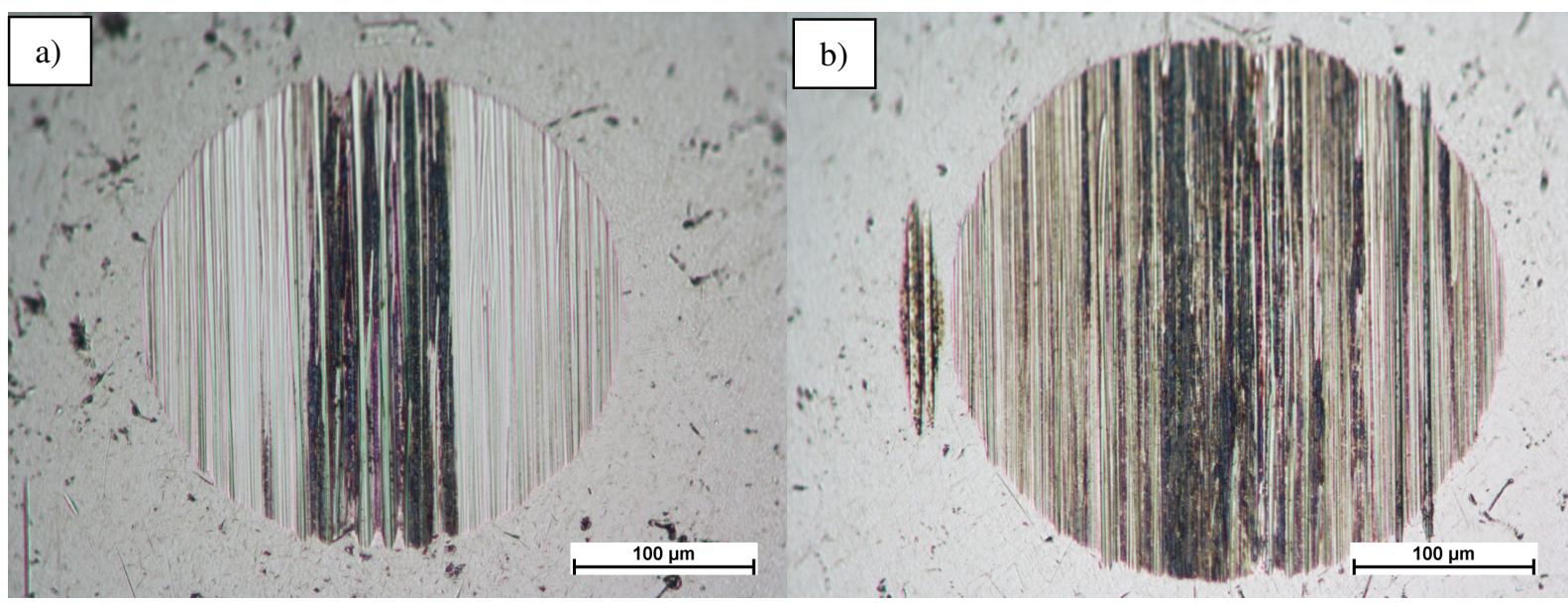

Fig. 6. Images of worn out surfaces: a) for diesel fuel; b) for aviation Jet A-1 fuel

\section{Conclusions}

1. The capacity of a high-pressure CRDI fuel injection pump decreased by $6.5 \%$ after 300 hour operation with Jet A-1 fuel at $110 \mathrm{MPa}$ under close to real operating conditions.

2. Maximum averaged frictional moment was measured, when using fuel Jet A-1, and the lowest one, when using normal diesel fuel.

3. Maximum mean diameter of the wear scar was obtained being equal to $0.6 \mathrm{~mm}$, when using neat fuel Jet A-1, and the minimum value of $0.28 \mathrm{~mm}$ was measured with diesel fuel.

4. The analysis of the data showed that the resulting area of the ball surface wear was lower, when using diesel fuel than that measured with aviation Jet A-1 fuel.

\section{References}

[1] Anastopoulos G., Lois E., Zannikos F., Kalligeros S., Teas C. HFRR lubricity response of an additized aviation kerosene for use in CI engines. Tribology International, 35(9), 2002, pp. 599-604.

[2] Labeckas G., Slavinskas S. Combustion phenomenon, performance and emissions of a diesel engine with aviation turbine JP-8 fuel and rapeseed biodiesel blends. Energy Conversion and Management, 105, 2015, pp. 216-229.

[3] Chong C. T., Hochgreb S. Spray flame structure of rapeseed biodiesel and Jet-A1 fuel. Fuel, 115, 2014, pp. 551-558.

[4] Heywood J. B. Internal combustion engine fundamentals. First edition. New York: McGraw-Hill Book Company, 1988. 930 p.

[5] Kuszewski H., Jaworski A., Ustrzycki A. Lubricity of ethanol-diesel blends-Study with the HFRR method. Fuel, 208, 2017, pp. 491-498.

[6] Matzke M., Litzow U., Jess A., Caprotti R., Balfour G. Diesel lubricity requirements of future fuel injection equipment. SAE International Journal of Fuels and Lubricants, 2(1), 2009, pp. 273-286. 